Zwijnenberg, N.C., Bours, G.J.J.W. Nurse practitioners and physician assistants in Dutch hospitals: their role, extent of substitution and facilitators and barriers experienced in the reallocation of tasks. Journal of Advanced Nursing: 2012, 68(6), 1235-1246

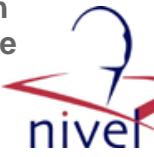

\begin{tabular}{|l|l|}
\hline $\begin{array}{l}\text { Postprint } \\
\text { Version }\end{array}$ & 1.0 \\
\hline Journal website & $\underline{\text { http://onlinelibrary.wiley.com/doi/10.1111//.1365-2648.2011.05823.x/abstract }}$ \\
\hline Pubmed link & $\underline{\text { http://www.ncbi.nlm.nih.gov/pubmed/21899594 }}$ \\
\hline DOI & $10.1111 /$ j.1365-2648.2011.05823.x \\
\hline
\end{tabular}

This is a NIVEL certified Post Print, more info at http://www.nivel.eu

\title{
Nurse practitioners and physician assistants in Dutch hospitals: their role, extent of substitution and facilitators and barriers experienced in the reallocation of tasks
}

\author{
NICOLIEN C. ZWIJNENBERG ${ }^{1}$, GERRIE J. J. W. BOURS ${ }^{2}$ \\ ${ }^{1}$ Assistant Research Associate, Maastricht University, Health Services Research, The \\ Netherlands \\ ${ }^{2}$ RN,Assistant Professor, Maastricht University, School for Public Health and Primary Care, \\ and Researcher University Zuyd, Expertise Centre on Autonomy and Participation, The \\ Netherlands
}

\begin{abstract}
Aims. This paper is a report of a study exploring the role of nurse practitioners and physician assistants, the extent of substitution and the barriers and facilitators experienced by them as a consequence of substitution in public hospitals.

Background. Nurse practitioners and physician assistants are emerging worldwide. However, despite the large amount of evidence showing the added value of these professionals, little evidence is available concerning the role, extent of substitution and facilitators and barriers experienced by them as a consequence of substitution.

Methods. Interviews were conducted and a questionnaire was completed by 43 nurse practitioners and 13 physician assistants employed in public hospitals in the south of the Netherlands in 2007.

Results. Nurse practitioners and physician assistants performed a broad spectrum of tasks, but differed significantly in the time spent and the kind of tasks performed. Nurse practitioners spent 25\% $(10.4$ hours; SD $=5.5)$ and physician assistants $40 \%(18.7$ hours; SD $=7 \cdot 6)$ of their time on medical procedures. They both also performed new tasks or tasks for which there previously was insufficient capacity. Many of them experienced policy/organizational, legal, financial or facility problems in the reallocation of tasks.

Conclusion. Nurse practitioners and physician assistants have wide ranging but different responsibilities in public hospitals. By performing medical procedures and new tasks or tasks for which there was not enough capacity, they function as
\end{abstract}


Zwijnenberg, N.C., Bours, G.J.J.W. Nurse practitioners and physician assistants in Dutch hospitals: their role, extent of substitution and facilitators and barriers experienced in the reallocation of tasks. Journal of Advanced Nursing: 2012, 68(6), 1235-1246

substitutes and supplements for doctors. However, barriers are affecting the extent of substitution. The challenge ahead is to remove the barriers experienced by nurse practitioners and physician assistants.

\section{INTRODUCTION}

Healthcare systems are facing an increased demand for care, waiting list problems and more specific and more intensive patient care. In addition, they are having to cope with shortages of medical staff, health sector reforms and cost containment. One response to these developments is to employ nurse practitioners (NPs) and physician assistants (PAs), who can perform medical procedures which were traditionally done by doctors. Just as in other countries, NPs and PAs are becoming more and more integrated into the healthcare system in the Netherlands.

\section{Background}

The first training programmes for NPs and PAs were developed in the United States in the mid-1960s (American Academy of Physician Assistants [AANP] 2009b; American College of Nurse Practitioners [ACNP] 2009). NPs and PAs have been increasingly employed since and are now found worldwide (Hooker 2008). In the Netherlands, the first Master's degree programmes on Advanced Nursing Practice (ANP) and PA started in 1997 and 2001, respectively. Currently, nine universities of professional education offer a Master's programme on ANP and five of them also a Master's programme on PA (Stichting Studiekeuze123 2009). Both programmes have a dual character in which the students learn the required competencies in a course programme and work in clinical settings as trainee NP or PA. The total annual number of trainee places for NPs and PAs is 400. Two-thirds of the places are reserved for NPs and one-third for PAs (Vulto \& Vianen 2009). Both programmes are funded by the Ministry of Education, Culture and Science, and have received grants from the Ministry of Health, Welfare and Sport. Since March 2009, NPs have been able to register as nurse specialists, a legally protected title implying statutory competences (Verpleegkundigen en Verzorgenden Nederland [V\&VN] 2009; Vulto \& Vianen 2009). In 2009, around 825 NPs and 300 PAs were in a training programme or were working in healthcare practice in the Netherlands (Vulto \& Vianen 2009). The introduction of NPs and PAs into the Dutch healthcare sector is based on the principle of substitution, i.e. reallocating tasks to different professionals (Council for Public Health and Health Care [RVZ] 2002; Health Council of the Netherlands 2008). The Dutch government expects substitution to raise the standards of quality and efficiency of health care. Substitution can also provide new career opportunities for nurses (Health Council of the Netherlands 2008).

Although NPs and PAs both have a wide range of responsibilities (AAPA 2009a; ACNP 2009), they represent two different types of professionals in Dutch health care. NPs work in both the medical and nursing domain, carrying out medical and nursing procedures for a specific group of patients, whereas PAs only work in the medical domain, performing medical procedures within their medical specialty. Furthermore, the position of an NP is at the top of the nursing hierarchy, whereas that of a PA is at the bottom of the medical hierarchy (Vulto \& Vianen 2009).

Both national and international evidence has shown the added value provided by NPs in hospital settings. Care delivered by NPs is at least as good and as safe as care 
Zwijnenberg, N.C., Bours, G.J.J.W. Nurse practitioners and physician assistants in Dutch hospitals: their role, extent of substitution and facilitators and barriers experienced in the reallocation of tasks. Journal of Advanced Nursing: 2012, 68(6), 1235-1246

delivered by doctors, and patients are satisfied with the care provided by NPs in Dutch hospitals (Schlooz-Vries et al. 2000, Vrijhoef 2002, Roodbol 2005, Broers et al. 2006a,b, Erkelens 2006, Health Council of the Netherlands 2008). The added value offered by NPs is also confirmed by a large body of international evidence (Chang et al. 1999, Sakr et al. 1999, Pioro et al. 2001, Caine et al. 2002, Litaker et al. 2003, Hoffman et al. 2005, Carryer et al. 2007, Osborn et al. 2010). International research has also shown the benefits of employing PAs in hospital-based settings. Patients are satisfied with the care delivered by PAs (Hooker et al. 1997, Counselman et al. 2000), PAs deliver quality care that is efficient (Miller et al. 1998, Woodin et al. 2005) and PAs contribute to cost savings in health care (Grzybicki et al. 2002, Hooker 2002, Roblin et al. 2004).

Despite the growing number of NPs and PAs, and the large amount of evidence for the added value of NPs and PAs, the question remains which explicit tasks are performed by NPs and PAs, to what extent substitution of medical procedures occurs and which barriers and facilitators NPs and PAs experience as a consequence of substitution. Although the roles of NPs (and Advance Practice Nursing) have been widely studied, these studies mainly focused on the core roles and generic features of this profession (Gardner \& Gardner 2005; Carryer et al. 2007, Mantzoukas \& Watkinson 2007). Little attention has been paid to the actual amount of time NPs spend on certain tasks as a consequence of substitution and, to our knowledge, such studies are completely lacking for PAs. According to Laurant et al. (2009), factors shaping the role of healthcare professionals include those factors influencing policy implementation (barriers and facilitators). These can be classified into three domains: attitudes of professionals and patients (acceptance, specialization, teamwork/collaboration), payment systems (financial incentives) and professional regulation and training (training programmes, legislation). Within the context of this framework, more evidence about the facilitators and barriers experienced in practice is desirable for future policies on the use of NPs and PAs.

Therefore, this study aimed to examine the explicit tasks NPs and PAs perform and the time they spend on these tasks. We also studied the extent of substitution by NPs and PAs, and the facilitators and barriers experienced by them. This study has provided more insight into the way NPs and PAs function in a hospital setting, which could support future policies about the implementation of roles of NPs and PAs in hospital settings worldwide.

\section{THE STUDY}

\section{Aims}

The study aimed to explore

the explicit tasks performed by NPs and PAs and the time they spend on these tasks; the extent of substitution provided by NPs and PAs;

the barriers and facilitators experienced by NPs and PAs as a consequence of

substitution;

the differences between NPs and PAs in the above aspects.

\section{Design}

This explorative, cross-sectional study used a mixed methods design which was primarily quantitative, but also involves a qualitative approach. 
Zwijnenberg, N.C., Bours, G.J.J.W. Nurse practitioners and physician assistants in Dutch hospitals: their role, extent of substitution and facilitators and barriers experienced in the reallocation of tasks. Journal of Advanced Nursing: 2012, 68(6), 1235-1246

\section{Participants}

All 62 NPs and PAs who were graduated or still in training and were employed in one of the six hospitals in the south of the Netherlands were invited to take part in this study.

Universities of professional education and hospitals were approached to provide the names, email addresses and phone numbers of eligible participants. An email was sent that explained the study and invited the recipient to participate. The potential participants were assured that all data would be analysed confidentially. If they agreed to participate in the study, they were contacted by the researcher to make an appointment for the interview.

\section{Data collection and outcome measures}

Data were collected by means of a questionnaire and interviews were conducted with all NPs en PAs. Data were gathered from February 2007 to July 2007.

\section{Questionnaire}

The tasks performed by NPs and PAs were explored using a questionnaire that was based on a job description including the competencies for NPs need to have in a hospital (Kemps 2006). These competencies were transformed into items, adapted and translated from a validated tool to measure nurse practitioner practice (Rosenfeld et al. 2003), and describing activities and tasks performed by NPs. This draft questionnaire was discussed with a panel of experts on nursing practice. The final questionnaire was based on consensus by the panel and was tested for feasibility by two NPs who were not included in this study. Apart from a recommendation to allow the questionnaire to be completed in digital format they found it to be feasible (Kemps 2006).

The questionnaire comprised 32 activities divided into seven main categories: (i) direct patient care, (ii) indirect patient care, (iii) training to improve one's own expertise, (iv) activities to improve the expertise of others, (v) research and innovation, (vi) organizational tasks and (vii) personal time, breaks and other activities (Table 1).

\section{[TABLE 1]}

Participants were asked to indicate how much time (in hours) they spent on each task. In addition, they were asked to indicate whether the tasks they performed were traditionally done by other healthcare professionals, did not exist previously or were tasks for which there was not enough capacity or time available in the past. Nurse practitioners and PAs were asked to fill in the questionnaire for a 1-week period. They could return the questionnaire to the researcher by post or by email, or could hand it during the interview.

The extent of substitution was evaluated by assessing the time spent on medical procedures in direct patient care. However, Kemps (2006) showed that medical procedures do not only comprise medical activities but also integrated activities and activities relating to coordination and continuation of care (Table 1). Therefore, half of the time spent on these activities was also counted as time spent on medical procedures. 
Zwijnenberg, N.C., Bours, G.J.J.W. Nurse practitioners and physician assistants in Dutch hospitals: their role, extent of substitution and facilitators and barriers experienced in the reallocation of tasks. Journal of Advanced Nursing: 2012, 68(6), 1235-1246

\section{Interview}

To increase the credibility and validity of the results, semi-structured interviews were conducted to assess the tasks performed by NPs and PAs and the extent of substitution. The interview was also used to identify the facilitators and barriers NPs and PAs experienced in task reallocation.

The semi-structured interview was based on research conducted in the Netherlands by Van Essen et al. (2006) and included the following topics: (i) background information, (ii) description of the work situation, (iii) relationship between and support from professionals/organization, (iv) effects of substitution, (v) education/competences and (vi) success factors, obstacles and solutions. The blueprint for the interview was slightly changed after the interviews with participants in the first hospital. The remaining participants had to indicate explicitly, on the basis of a list of job responsibilities, which tasks they performed and whether they were primarily responsible for these tasks. The participants also had to indicate explicitly if substitution occurred.

Each interview was scheduled to last for 90 minutes, and was conducted at the NP/PA's workplace. Interviews were recorded on a voice recorder and field notes were taken during the interview.

\section{Ethical considerations}

The study was conducted in accordance with the Code of Ethics of the Declaration of Helsinki. Since no patients were involved in this study, ethics approval by the hospitals was not necessary. Participants were informed about the research procedures and were assured that their identity would not be disclosed. In addition, informed consent was obtained (oral or written) from all participants.

\section{Data analysis}

Data were analysed using SPSS version $11 \cdot 5$. The questionnaire results were quantified by reviewing and encoding the outcomes. To allow straightforward comparisons between NPs and PAs with respect to time spent on activities, data for participants working part-time were converted to full-time employment.

The interview results were also quantified and were reviewed and encoded by three researchers. Two interviews were encoded and discussed by all three researchers, to reduce inter-rater differences to less than $10 \%$. Some parts of the interview (e.g. barriers and facilitators) were transcribed and categorized, so the narrative character of the interview was not completely lost.

Results were analysed using the independent sample $t$-test and the chi-square test to assess differences between NPs and PAs. The Fisher's exact test was used when numbers were small (expected value less than 5). Comparisons were deemed statistically significant at the $5 \%$ level $(P<0 \cdot 05)$.

\section{RESULTS}

\section{Characteristics of NPs and PAs}

Forty-three NPs $(97 \cdot 7 \%)$ and 13 PAs $(72 \cdot 2 \%)$ participated in the study. Six of the 62 potential participants who met the inclusion criteria refused to participate. The majority of the participants (64\%) were female (Table 2). Forty-eight per cent of all 
Zwijnenberg, N.C., Bours, G.J.J.W. Nurse practitioners and physician assistants in Dutch hospitals: their role, extent of substitution and facilitators and barriers experienced in the reallocation of tasks. Journal of Advanced Nursing: 2012, 68(6), 1235-1246

participants were second year students. NPs primarily worked in an outpatient setting, while PAs primarily worked in a clinical setting. Many NPs (40\%) and PAs (31\%) also worked in both settings. NPs and PAs worked in a wide variety of clinical specialties. Numbers were too small to allow reliable comparisons between NPs and PAs as regards work situation and specialties.

\section{[TABLE 2]}

\section{TASKS PERFORMED BY NPS AND PAS}

The questionnaire results and interview results about the tasks performed by NPs and PAs are presented in Tables 3 and 4, respectively. NPs and PAs had a wide range of responsibilities. NPs and PAs spent most of their time on activities in direct and indirect patient care, and training to improve their own expertise: $57 \cdot 8 \%$ vs. $66 \%$ and $25 \cdot 7 \%$ vs. $24 \cdot 5 \%$, respectively (Table 3 ). The care delivered by NPs $(95 \cdot 3 \%)$ and PAs (84.6\%) was partly or completely based on protocols (Table 4 ).

\section{[TABLE 3]}

Nurse practitioners and PAs also differed in terms of direct patient care activities. PAs (34.2\%; 16. 2 hours) spent more time on medical activities than NPs (14.2\%; $5 \cdot 9$ hours Table 3 ). More specifically, PAs spent more time than NPs on developing medical treatment plans and on medical technical activities: $4 \cdot 7 \%(2 \cdot 2$ hours) vs. $1 \cdot 1 \%(0.5$ hours $)$ and $13.5 \%(6.4$ hours $)$ vs. $0 \cdot 8 \%(0 \cdot 3$ hours $)$, respectively $(P<$ $0 \cdot 05)$. This finding was confirmed by the interview results: more PAs (all) than NPs (50\%) indicated that they performed medical technical activities (Table 4). As expected, NPs spent more time and performed more nursing and integrated activities than PAs (Tables 3 and 4). NPs and PAs also differed in the time they spent on some activities relating to the coordination and continuation of care, although the total time spent on these activities did not differ between NPs and PAs (Table 3). NPs (4.1\%; $1 \cdot 7$ hours) spent more time than PAs ( $1.5 \% ; 0.7$ hours) on follow up and on monitoring patients' treatment plans $(P<0 \cdot 01)$. NPs $(1 \cdot 8 \% ; 0 \cdot 8$ hours $)$ also spent more time than PAs ( $0 \%$; 0 hours) on case management $(P<0 \cdot 001)$, and NPs (76.7\%) also engaged in case management more often than PAs (16.7\%; Table 4). In contrast, PAs ( $4.0 \% ; 1.9$ hours) spent more time on patient discharge than NPs (1.3\%; 0.6 hours) $(P<0.05)$, and more PAs $(69 \cdot 2 \%)$ than NPs $(34 \cdot 9 \%)$ discharged patients (Table 4).

As regards indirect patient care activities, NPs and PAs differed in the time they spent on 'other activities'. More specifically, we saw that PAs spent more time on making rounds $(9 \cdot 4 \% ; 4 \cdot 4$ hours) than NPs $(1 \cdot 0 \% ; 0 \cdot 4$ hours; $P<0 \cdot 05)$. More PAs than NPs were also engaged in doing rounds (88.9\% vs. 32.3\%; Table 4$)$. In contrast, NPs spent more time on writing proposals to improve health care $(2 \cdot 3 \% ; 1 \cdot 0$ hours) than PAs $(0 \cdot 4 \% ; 0 \cdot 2$ hours; $P<0 \cdot 01)$. Time spent on scientific research and innovation, however, did not differ between NPs and PAs (Table 3). Scientific research can also be classified under training to improve one's own expertise, as it is part of the training programme. Concerning the other main categories, NPs spent more time $(5 \cdot 9 \%)$ on organizational tasks than PAs (1.5\%; Table 3$)$.

Physician assistants generally worked more hours ( $47 \cdot 3$ hours) than NPs ( $41 \cdot 8$ hours; Table 3 ). About half of the PAs (46.2\%) performed only tasks that were traditionally 
Zwijnenberg, N.C., Bours, G.J.J.W. Nurse practitioners and physician assistants in Dutch hospitals: their role, extent of substitution and facilitators and barriers experienced in the reallocation of tasks. Journal of Advanced Nursing: 2012, 68(6), 1235-1246

done by other healthcare professionals, while $38.5 \%$ of them combined these tasks with new tasks. In contrast, NPs mainly performed tasks that were traditionally performed by other healthcare professionals combined with tasks for which there was previously not enough capacity (34.9\%), or tasks traditionally done by other healthcare professionals combined with new tasks (34.9\%) (Table 4). However, numbers were too small to allow reliable comparisons.

\section{Extent of substitution}

All NPs and PAs performed medical procedures. NPs spent 25\% (10.4 hours; SD = $5 \cdot 5)$ and PAs $40 \%(18 \cdot 7$ hours; $\mathrm{SD}=7 \cdot 6)$ of their total time on medical procedures $(\mathrm{P}$ $<0 \cdot 001)$. Time spent on nursing procedures was $15 \cdot 6 \%(6 \cdot 5$ hours; SD $=3 \cdot 4)$ for NPs and $5 \cdot 7 \%(2 \cdot 7$ hours; $\mathrm{SD}=2 \cdot 0)$ for PAs.

Nurse practitioners $(n=24)$ had to indicate whether substitution occurred, i.e. whether tasks were reallocated, in their work situation. $70 \cdot 8 \%(n=17)$ indicated that tasks were reallocated on a permanent basis (substitution). In addition, $87 \%$ of the NPs $(n=20)$ reported that tasks were reallocated, but that they were not predominantly responsible for these tasks (delegation). 56.5\% $(n=13)$ reported a combination of structural reallocation and delegation of tasks.

\section{Barriers experienced in the reallocation of tasks}

Many NPs and PAs experienced problems in the reallocation of tasks. Thirty-two NPs (74.4\%) and 8 PAs (61.5\%) experienced problems relating to the policy and organizational domain. These organizational and policy problems predominantly included lack of long-term planning and vision by the management/board of directors, resistance from medical specialists or junior doctors, insecurity about continuation or job content, unclear position in the organization, and problems concerning study hours and combining study and work.

Legal problems were experienced by 16 NPs (38.1\%) and 6 PAs (50\%). The most important legal problem concerned the lack of a legal framework giving them the authority to prescribe medication and to order laboratory tests, X-rays and nourishment.

Financial problems were experienced by more than half of the NPs $(53 \cdot 5 \% ; n=23)$ and PAs (53.8\%; $n=7)$. Financial problems mainly concerned uncertainty about the budget (medical/nursing) to fund the employment of NPs or PAs, whether the medical partnership had to or was willing to contribute to the salaries of NPs and PAs, and the salary levels of NPs and PAs.

Facilities-related problems experienced by NPs $(50 \% ; n=21)$ and PAs $(63 \cdot 6 \% ; n=$ 7) mainly concerned not having their own office or outpatient treatment space and not having their own computer.

\section{Facilitators experienced in the reallocation of tasks}

Of the NPs and PAs, $73 \cdot 8 \%(n=31)$ and $90 \cdot 9 \%(n=10)$, respectively, indicated that there was a permanent policy defining their role embedded in a protocol, a policy plan, a vision document, verbal arrangements or a combination of these. All PAs ( $n=$ $13)$ and $92 \cdot 7 \%$ of the NPs $(n=38)$ indicated that their tasks and scope of practice had been agreed upon. The relationship between NPs and PAs and other healthcare professionals (e.g. doctors, nurses and paramedics) was generally evaluated favourably. In addition, $67 \cdot 6 \%$ of the NPs $(n=25)$ and $50 \%$ of the PAs $(n=6)$ thought that the hospital provided sufficient support for their role. 
Zwijnenberg, N.C., Bours, G.J.J.W. Nurse practitioners and physician assistants in Dutch hospitals: their role, extent of substitution and facilitators and barriers experienced in the reallocation of tasks. Journal of Advanced Nursing: 2012, 68(6), 1235-1246

Nurse practitioners and PAs mentioned different facilitators for the reallocation of tasks. These mainly concerned (i) support, effort and trust from management and fellow healthcare professionals, (ii) manager/team giving PAs and NPs the freedom to develop their role, (iii) enthusiasm from all people involved, (iv) hospital providing training opportunities/enough space for study and internships, (v) specialists being motivated to provide guidance during training, (vi) clear vision of job responsibilities established beforehand/job specifications in writing, (vii) their own success, (viii) own personality/own initiative/years of work experience, (ix) sufficient challenge, and opportunities for personal development and (x) acceptance of office hours by patients.

\section{Discussion}

Our study showed that NPs and PAs had wide ranging but different responsibilities in Dutch public hospitals. NPs spent 25\% of their working week on medical procedures, while PAs spent $40 \%$, showing that NPs and PAs function as substitutes for doctors. However, many NPs and PAs experienced policy/organizational, legal, financial or facilities-related barriers in the reallocation of tasks, which affected the extent of substitution.

\section{Study limitations}

The strengths of this study were the mixed method we used and the high response rate, resulting in a representative sample. However, there were also several limitations.

The majority of the NPs and PAs in our study were still in training, so their job content was still developing during the study. Consequently, the extent of substitution reported by our participants may be an underestimation. As more NPs and PAs graduate, the results regarding the extent of substitution may become even more positive.

Data were acquired by means of questionnaires and interviews, which may have led to recall bias and subjectivity and to biased results. A more objective measurement design, i.e. an observational study, might have resulted in slightly different outcomes.

The study used a very detailed questionnaire to precisely determine the responsibilities of NPs and PAs. Participants found it difficult to divide their work into such detailed subtasks. In practice, some tasks are not always performed separately, but are more or less integrated (e.g. taking medical history and performing physical examination at the same time). This may have somewhat hampered the validity of the results.

Finally, the blueprint for the interview was different for participants recruited from the first hospital and those from the other hospitals; to gain a more comprehensive view of the responsibilities of NPs and PAs, some questions were added after the first participants had been interviewed. For participants from the first hospital, the added questions were not scored at all (subjective extent of substitution) or scored on the basis of the questionnaire and other interview findings (tasks performed), when possible. This may have caused some misinterpretation of these results. However, the change in the blueprint for the other participants did result in more detailed and precise information. 
Zwijnenberg, N.C., Bours, G.J.J.W. Nurse practitioners and physician assistants in Dutch hospitals: their role, extent of substitution and facilitators and barriers experienced in the reallocation of tasks. Journal of Advanced Nursing: 2012, 68(6), 1235-1246

\section{Discussion of results}

Nurse practitioners and PAs in our study had wide-ranging responsibilities. This is in line with other findings (Kenbeek \& Rademakers 2006, AAPA 2009b, American College of Nurse Practitioners 2009; Britell 2010, Nyberg et al. 2010). Kenbeek and Rademakers (2006) found that typical NPs perform 'cure' and 'care' tasks, whereas typical PAs perform only 'cure' tasks, which is in line with the present study. The large numbers of NPs and PAs who were still in training may have contributed to the relatively high percentage of their time spent on training to improve their own expertise, which is in agreement with research by Tempelman (2005). However, NPs at a university medical centre in the Netherlands only spent around $10 \%$ of their time on training to improve their own expertise (Kemps 2006); the difference in result may have been caused by the smaller proportion of NPs in training.

The present study showed that NPs spent a quarter and PAs almost half of their time on medical procedures. This shows that NPs and PAs function as substitutes for doctors, which is also confirmed by previous research (Richardson et al. 1998, Van Offenbeek et al. 2004). Richardson et al. (1998) showed that between $25 \%$ and $70 \%$ of the tasks of doctors, mostly general practitioners, could be carried out by nonphysician practitioners. However, Roodbol (2005) reported that substitution did not occur at all in Dutch health care, because physicians remained responsible for the medical tasks. Roodbol also found that it was patient groups which were delegated, rather than medical tasks. In contrast to Roodbol (2005), we found that it was not only a matter of delegating tasks, but that medical procedures were also permanently reallocated. Roodbol's finding concerning the delegation of patient groups instead of medical tasks was not investigated in the present study.

Evidence shows that substitution of tasks is justifiable in terms of quality of care and patient outcomes (Laurant et al. 2009). It is also likely that employing 'the lowest cost provider' (Reay et al. 2003) will mean that healthcare systems benefit in terms of efficiency and cost containment. After all, the salaries of NPs and PAs are lower than those of doctors. However, findings on healthcare costs have been mixed (Laurant et al. 2009) and previous research had several methodological limitations (Dierick-van Daele et al. 2008, Laurant et al. 2009). Savings in salaries may, for example be offset by lower productivity as NPs or PAs might take more time for their patients. In addition, the role of NPs or PAs is additional to the existing care process, as the care process is not being redesigned, so this does not result in efficiency gains (Health Council of the Netherlands 2008). More research concerning the economic evaluation of employing NPs and PAs in Dutch hospitals is needed to determine if substitution of tasks contributes to more efficient care and results in cost savings.

Nurse practitioners and PAs also performed new tasks or tasks for which there was previously not enough capacity, which is in agreement with previous research (Van Offenbeek et al. 2004, Van Offenbeek 2008). This suggests that NPs and PAs also function as supplements to doctors by providing additional services which are intended to complement or extend those provided by doctors (Richardson et al. 1998, Laurant et al. 2009).

Substitution of tasks may also be important in light of recent developments concerning the opportunities offered by health care and the use of Internet (eHealth or Health 2-0). In these new forms of healthcare delivery, individuals (i.e. patients and healthcare professionals) are brought together by social media to discuss health 
Zwijnenberg, N.C., Bours, G.J.J.W. Nurse practitioners and physician assistants in Dutch hospitals: their role, extent of substitution and facilitators and barriers experienced in the reallocation of tasks. Journal of Advanced Nursing: 2012, 68(6), 1235-1246

and health care (Eysenbach 2008, Council for Public Health and Health Care [RVZ] 2010). NPs and PAs are perfectly able to perform care tasks based on this kind of health care, against lower costs. This would allow doctors to focus on their core task of treating patients with more complex medical problems.

The majority of the NPs and PAs experienced policy/organizational, financial, legal or facilities-related barriers in the reallocation of tasks. The NPs and PAs also mentioned facilitators for the reallocation of tasks, e.g. support by management and healthcare professionals. These findings are consistent with those of previous studies (Marsden et al. 2003, Kenbeek \& Rademakers 2006, Thrasher \& Purc-Stephenson 2007, Keating et al. 2010). Marsden et al. (2003) reported, for example, that NPs need the freedom to innovate, sufficient support and appropriate training to allow true autonomy, and that practice is hindered by limited prescribing authority and restrictions on requesting tests. In a Dutch context, Kenbeek and Rademakers (2006) showed that legislation, funding, support, supervision, characteristics of the NP/PA and evident quality improvements were success and failure factors for employing NPs and PAs in Dutch hospitals.

Some of the barriers experienced by NPs and PAs in this study, for example, resistance from other healthcare professionals, might be due to the fact that the introduction of NPs and PAs was still in a pioneering stage. However, doctors still seem reluctant to change their ways by reallocating tasks (Health Council of the Netherlands 2008). Apparently, doctors find it hard to delegate the final responsibility for medical tasks towards non-physician practitioners (Van Rooijen 2003). The majority of the NPs and PAs in this study delivered care that was partly or completely based on protocols. Making use of protocols can probably increase interprofessional trust (Health Council of the Netherlands 2008), which can ultimately have a positive influence on the extent of substitution. For this purpose, it has to be clear to healthcare professionals which tasks others can or cannot perform. Professional organizations of NPs and PAs can take up the responsibility to inform other professions about the competencies possessed by NPs and PAs and the professional scope of practice of NPs and PAs.

The legal obstacles for NPs and PAs found in our study are gradually being removed. A change has been proposed to the Individual Health Care Professions Act, which makes it possible for NPs and PAs to autonomously prescribe medication and carry out other reserved activities (Ministry of Health, Welfare and Sport [VWS] 2009). This revised act has recently been approved by the Dutch Parliament and will come into force in 2011. Even with this revised act, however, removing the organizational, financial and facilities-related barriers need to be addressed by managers and policy makers in the hospital setting.

\section{Policy implications}

This study allows some valuable recommendations to be made for future policies on the implementation of the role of NPs and PAs in hospitals and for useful future research in this area worldwide.

\section{Policy recommendations}

- Managers of hospitals should formulate policies about the roles of NPs and PAs in advance, and arrange suitable facilities for these new professionals at 
Zwijnenberg, N.C., Bours, G.J.J.W. Nurse practitioners and physician assistants in Dutch hospitals: their role, extent of substitution and facilitators and barriers experienced in the reallocation of tasks. Journal of Advanced Nursing: 2012, 68(6), 1235-1246

an early stage, asking themselves: why do we need a NP/PA; what tasks can NPs/PAs fulfil and who is responsible for supervision; what facilities do we need for these new professionals (e.g. job description, office space, training \& internships) and who is willing to finance the work? Addressing such questions in advance can reduce the barriers experienced by NPs and PAs. Challenges for managers comprise clarifying the reallocation of tasks, managing shifting working relationships in the team and continuing to manage the team in an evolving situation (Reay et al. 2003).

- $\quad$ Nurse practitioners and PAs must have the certainty that their job will continue after graduation.

- Support from all healthcare professionals involved is of major importance for successful implementation of the roles of NPs and PAs. This will also reduce resistance from other healthcare professionals. Change management skills are valuable to address resistance to change by professionals (Laurant et al. 2009).

- $\quad$ The most important legal barrier, i.e. the lack of authority to prescribe medication, must be removed by legislative means. In the Dutch situation, the proposed change to the Individual Healthcare Professions Act will soon come into force.

Future research

- We recommend repeating the present study when more NPs and PAs have graduated, preferably using an observational study design to obtain more objective data. Involvement of patients and medical supervisors could help achieve a more comprehensive view of the way NPs and PAs function in health care.

\section{CONCLUSION}

Nurse practitioners and PAs are two different healthcare professionals, both performing a broad spectrum of tasks in public hospitals. By performing medical procedures traditionally done by doctors, NPs and PAs function as substitutes for them. In addition, they also supplement the work of doctors by performing new tasks (PAs) and new tasks or tasks for which there was previously not enough capacity (NPs). The challenges ahead are to remove the barriers for an even better implementation of the role of NPs and PAs in the healthcare sector. In this way, the role of NPs and PAs can be fully integrated into the healthcare system and the full benefits of employing NPs and PAs can be reaped.

\section{Acknowledgements}

We acknowledge the contributions and dedication of all NPs and PAs who participated in this study, and of the members of the research team in the University Hospital Maastricht; Barbara Solberg, MSc. Theo van Spauwen, MSc and Jan Pierre Lucassen, MSc. Finally, we also thank Professor Rianne de Wit, for her supervising role and for the design of this study. 
Zwijnenberg, N.C., Bours, G.J.J.W. Nurse practitioners and physician assistants in Dutch hospitals: their role, extent of substitution and facilitators and barriers experienced in the reallocation of tasks. Journal of Advanced Nursing: 2012, 68(6), 1235-1246

\section{Conflict of interest}

No conflict of interest has been declared by the authors.

\section{Funding}

This research received no specific grant from any funding agency in the public, commercial, or not-for-profit sector. This study was carried out as part of the postgraduate project of NC Zwijnenberg.

\section{Author Contributions}

NZ was responsible for the study conception and design and for the drafting of the manuscript. NZ also performed the data analysis and data collection. GB made critical revisions to the paper for important intellectual content, provided statistical expertise and supervised the study.

\section{REFERENCES}

American Academy of Physician Assistants. (2009a) Our practice areas. Retreived from http://www.aapa.org/about-pas/our-practice-areas on 10 November 2009.

American Academy of Physician Assistants. (2009b) Our History. Retreived from http://www.aapa.org/about-pas/our-history on 10 November 2009.

American College of Nurse Practitioners. (2009) Frequently asked questions about Nurse Practitioners. Retreived from http://www.acnpweb.org/files/public/FAQ_about_NPs_May06.pdf on 10 November 2009. Britell J.C. (2010) Role of advanced nurse practitioners and physician assistants in Washington state. Journal of Oncology Practice6(1), 37-38.

Broers C., Hogeling-Koopman J., Burgersdijk C., Cornel J.H., van der P.J. \& Umans V.A. (2006a) Safety and efficacy of a nurse-led clinic for post-operative coronary artery bypass grafting patients. International Journal of Cardiology106(1), 111-115.

Broers C.J.M., Smulders J., Ploeg van der T.J., Arnold A.E.R. \& Umans V.A.W. (2006b) 'Nurse practitioner' even bekwaam als assistent-geneeskundige voor de behandeling van stabiele patiënten na een recent myocardinfarct, maar met meer tevredenheid bij patiënten. Nederlands Tijdschrift voor de Geneeskunde150(2), 2544-2548.

Caine N., Sharples L.D., Hollingworth W., French J., Keogan M., Exley A., Hodgkins D. \& Bilton D. (2002) A randomised controlled crossover trial of nurse practitioner versus doctorled outpatient care in a bronchiectasis clinic. Health Technology Assessment6(27), 1-71.

Carryer J., Gardner G., Dunn S. \& Gardner A. (2007) The core role of the nurse practitioner: practice, professionalism and clinical leadership. Journal of Clinical Nursing16(10), 18181825.

Chang E., Daly J., Hawkins A., McGirr J., Fielding K., Hemmings L., O'Donoghue A. \& Dennis M. (1999) An evaluation of the nurse practitioner role in a major rural emergency department. Journal of Advanced Nursing30(1), 260-268.

Council for Public Health and Health Care [RVZ]. (2002) Taakherschikking in de gezondheidszorg. Council for Public Health and Health Care, Zoetermeer.

Council for Public Health and Health Care [RVZ]. (2010) Health 2.0. It's up to you! Council for Public Health and Health Care, Den Haag.

Counselman F.L., Graffeo C.A. \& Hill J.T. (2000) Patient satisfaction with physician assistants (PAs) in an ED fast track. American Journal of Emergency Medicine18(6), 661665.

Dierick-van Daele A.T.M., Spreeuwenberg C., Derckx E.W.C.C., Metsemakers J.F.M. \& Vrijhoef B.J.M. (2008) Critical appraisal of the literature on economic evaluations of substitution of skills between professionals: a systematic literature review. Journal of Evaluation in Clinical Practice14, 481-492. 
Zwijnenberg, N.C., Bours, G.J.J.W. Nurse practitioners and physician assistants in Dutch hospitals: their role, extent of substitution and facilitators and barriers experienced in the reallocation of tasks. Journal of Advanced Nursing: 2012, 68(6), 1235-1246

Erkelens H. (2006) Nurse Practitioner maakt zorgproces efficiënter. Polsslag 1. Universitair Medisch Centrum Groningen, Groningen.

Eysenbach G. (2008) Medicine 2.0: social networking, collaboration, participation, apomediation, and openness. Journal of Medical Internet Research10(3), e22.

Gardner A. \& Gardner G. (2005) A trial of nurse practitioner scope of practice. Journal of Advanced Nursing49(2), 135-145.

Grzybicki D.M., Sullivan P.J., Oppy J.M., Bethke A.M. \& Raab S.S. (2002) The economic benefit for family/general medicine practices employing physician assistants. American Journal of Managed Care8(7), 613-620.

Health Council of the Netherlands. (2008) Taakherschikking in de gezondheidszorg. Inzet van praktijkassistenten en -ondersteuners, nurse practitioners en physician assistants. Health Council of the Netherlands, Den Haag.

Hoffman L.A., Tasota F.J., Zullo T.G., Scharfenberg C. \& Donahoe M.P. (2005) Outcomes of care managed by an acute care nurse practitioner/attending physician team in a subacute medical intensive care unit. American Journal of Critical Care14(2), 121-130.

Hooker R.S. (2002) A cost analysis of physician assistants in primary care. Journal of the American Academy of Physician Assistants15(11), 39-42.

Hooker R.S. (2008) The extension of rheumatology services with physician assistants and nurse practitioners. Best Practice \& Research Clinical Rheumatology22(3), 523-533.

Hooker R.S., Potts R. \& Ray W. (1997) Patient satisfaction: comparing physician assistants, nurse practitioners and physicians. The Permanente Journal1(1), 38-42.

Keating S.F., Thompson J.P. \& Lee G.A. (2010) Perceived barriers to the sustainability and progression of nurse practitioners. International Emergency Nursing18(3), 147-153.

Kemps H. (2006). Onderzoeksverslag evaluatie project nurse practitioner. UMC St Radboud. Nijmegen.

Kenbeek J. \& Rademakers J. (2006) Overeenkomsten en verschillen in taken, verantwoordelijkheden en competenties van Nurse Practitioners and Physician Assistants in ziekenhuizen, nu en in de toekomst. MOBG, Utrecht.

Laurant M., Harmsen M., Wollersheim H., Grol R., Faber M. \& Sibbald B. (2009) The impact of nonphysician clinicians: do they improve the quality and cost-effectiveness of healthcare services?Medical Care Research and Review66(6 Suppl), 36S-89S.

Litaker D., Mion L., Planavsky L., Kippes C., Mehta N. \& Frolkis J. (2003) Physician - nurse practitioner teams in chronic disease management: the impact on costs, clinical effectiveness, and patients' perception of care. Journal of Interprofessional Care17(3), 223-237.

Mantzoukas S. \& Watkinson S. (2007) Review of advanced nursing practice: the international literature and developing the generic features. Journal of Clinical Nursing16(1), 28-37.

Marsden J., Dolan B. \& Holt L. (2003) Nurse practitioner practice and deployment: electronic mail Delphi study. Journal of Advanced Nursing43(6), 595-605.

Miller W., Riehl E., Napier M., Barber K. \& Dabideen H. (1998) Use of physician assistants as surgery/trauma house staff at an American College of Surgeons-verified Level II trauma center. Journal of Trauma44(2), 372-376.

Ministry of Health, Welfare and Sport [VWS]. (2009) Wijziging van de Wet op de beroepen in de individuele gezondheidszorg onder andere in verband met de opneming van de mogelijkheid tot taakherschikking. Nr 3 Memorie van Toelichting. [parliamentary paper]. Retreived from https://zoek.officielebekendmakingen.nl/kst-32261-3.pdf on 11 November 2009.

Nyberg S.M., Keuter K.R., Berg G.M., Helton A.M. \& Johnston A.D. (2010) Acceptance of physician assistants and nurse practitioners in trauma centers. Journal of the American Academy of Physician Assistants23(1), 35-37.

Osborn G.D., Jones M., Gower-Thomas K. \& Vaughan-Williams E. (2010) Breast disease diagnostic ability of nurse practitioners and surgeons. Journal of Advanced Nursing66(7), 1452-1458.

Pioro M.H., Landefeld C.S., Brennan P.F., Daly B., Fortinsky R.H., Kim U. \& Rosenthal G.E. (2001) Outcomes-based trial of an inpatient nurse practitioner service for general medical patients. Journal of Evaluation in Clinical Practice7(1), 21-33. 
Zwijnenberg, N.C., Bours, G.J.J.W. Nurse practitioners and physician assistants in Dutch hospitals: their role, extent of substitution and facilitators and barriers experienced in the reallocation of tasks. Journal of Advanced Nursing: 2012, 68(6), 1235-1246

Reay T., Golden-Biddle K. \& Germann K. (2003) Challenges and leadership strategies for managers of nurse practitioners. Journal of Nursing Management11, 396-403.

Richardson G., Maynard A., Cullum N. \& Kindig D. (1998) Skill mix changes: substitution or service development?Health Policy45(2), 119-132.

Roblin D.W., Howard D.H., Becker E.R., Kathleen A.E. \& Roberts M.H. (2004) Use of midlevel practitioners to achieve labor cost savings in the primary care practice of an MCO. Health Services Research39(3), 607-626.

Roodbol P.F. (2005) Dwaallichten, struikeltochten, tolwegen en zangsporen. Onderzoek naar taakherschikking tussen verpleging en artsen. Doctoral Thesis, Universiteit Groningen. Groningen.

Rosenfeld P., McEvoy M.D. \& Glassman K. (2003) Measuring practice patterns among acute care nurse practitioners. Journal of Nursing Administration33(3), 159-165.

Sakr M., Angus J., Perrin J., Nixon C., Nicholl J. \& Wardrope J. (1999) Care of minor injuries by emergency nurse practitioners or junior doctors: a randomised controlled trial. The Lancet354(9187), 1321-1326.

Schlooz-Vries M.S., Raatgever M., Versluis J.P., Hennipman A. \& Borel Rinkes I.H.M. (2000) Patiënten tevreden over nurse practitioner. Duidelijke verbeteringen op chirurgische mammapolikliniek. Medisch Contact55, 48-50.

Stichting Studiekeuze123. (2009) Studiekeuze123. Retreived from http://www.studiekeuze123.nl/index.aspx on 11 November 2009.

Tempelman C.J.J. (2005) Het zelfbeeld van nurse practitioners anno 2005. Deel 1. Kerncijfers. HanzeConnect, Groningen.

Thrasher C. \& Purc-Stephenson R.J. (2007) Integrating nurse practitioners into Canadian emergency departments: a qualitative study of barriers and recommendations. Canadian Journal of Emergency Medicine9(4), 275-281.

Van Essen G., Derks M. \& Bloemendaal A. (2006). Praktijkervaringen met taakherschikking in de zorgsector. Aansprekende voorbeelden in het medische domein. Prismant, Utrecht.

Van Offenbeek M. (2008) De potentie van een NP. Medisch Contact63(4), 147-152.

Van Offenbeek M.A.G., Ten Hoeve Y. \& Roodbol P.F. (2004) Nurse practitioners combineren cure en care. Medisch Contact59(01/02), 18-21.

Van Rooijen A. (2003) De kunst van het loslaten. Oordeel van artsen over nieuwe zorgverleners. Medisch Contact45, 1725-1728.

Verpleegkundigen en Verzorgenden Nederland [V\&VN]. (2009) Verpleegkundig specialist. Genezing en zorg afgestemd. V\&VN, Utrecht.

Vrijhoef H.J.M. (2002) Is it justifiable to treat chronic patients by nurse specialists? Evaluation of effects on quality of care. Doctoral Thesis, Maastricht University. Maastricht.

Vulto M. \& Vianen G. (2009) Toekomstige behoefte verpleegkundig specialisten bij somatische aandoeningen. Een zoektocht in onontgonnen gebied. STG/Health Management Forum, Utrecht.

Woodin J., McLeod H., McManus R. \& Jelphs K. (2005). Evaluation of US-trained Physician Assistants working in the NHS in England. The introduction of US-trained Physician Assistants to Primary Care and Accident and Emergency departments in Sandwell and Birmingham. Final report. University of Birmingham, Birmingham. 
Zwijnenberg, N.C., Bours, G.J.J.W. Nurse practitioners and physician assistants in Dutch hospitals: their role, extent of substitution and facilitators and barriers experienced in the reallocation of tasks. Journal of Advanced Nursing: 2012, 68(6), 1235-1246

\section{TABLES}

Table 1. Main categories and corresponding activities in the questionnaire to assess the tasks of nurse practitioners and physician assistants

\begin{tabular}{|c|c|}
\hline \multirow{19}{*}{ 1. Direct patient care } & Medical activities \\
\hline & Taking medical history \\
\hline & Performing physical examination \\
\hline & Ordering laboratory tests \\
\hline & Medical technical activities \\
\hline & Development of medical treatment plan \\
\hline & Implementing medical treatment plan \\
\hline & Integrated activities \\
\hline & Taking medical/nursing history \\
\hline & Development of medical/nursing treatment plan \\
\hline & Nursing activities \\
\hline & Taking nursing history \\
\hline & Development of nursing treatment plan \\
\hline & Performing nursing interventions \\
\hline & Activities relating to coordination and continuity \\
\hline & Provide information about consequences of the disease \\
\hline & Follow up and monitoring patient's treatment plan \\
\hline & Discharging patients (conversation \& letter of discharge) \\
\hline & Case management \\
\hline \multirow{14}{*}{ 2. Indirect patient care } & Consultation \\
\hline & Consulting a physician \\
\hline & Consulting a paramedic \\
\hline & Consulting a care discipline (e.g. nursing consultant) \\
\hline & Referral \\
\hline & Referral to physician \\
\hline & Referral to paramedic \\
\hline & Referral to psychologist, pastoral care \\
\hline & Referral to care discipline (e.g. nursing consultant) \\
\hline & Other activities \\
\hline & Consulting others about patients \\
\hline & Making rounds \\
\hline & Administrative tasks in patient care \\
\hline & Signalling shortcomings in direct patient care \\
\hline
\end{tabular}


Zwijnenberg, N.C., Bours, G.J.J.W. Nurse practitioners and physician assistants in Dutch hospitals: their role, extent of substitution and facilitators and barriers experienced in the reallocation of tasks. Journal of Advanced Nursing: 2012, 68(6), 1235-1246

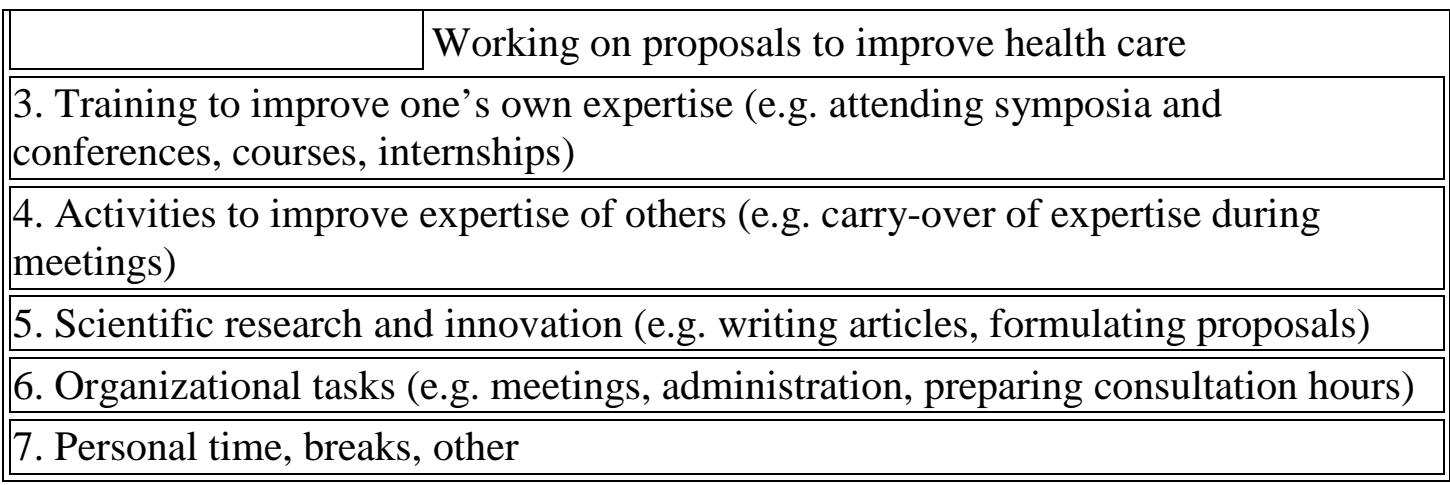

Table 2. Characteristics of nurse practitioners (NPs) and physician assistants (PAs) [figures are numbers (\%)]

\begin{tabular}{|c|c|c|c|}
\hline Characteristic & NPs $(n=43)$ & PAs $(n=13)$ & $P$ value \\
\hline \multicolumn{4}{|l|}{ Gender } \\
\hline Male & $15(35)$ & $5(38)$ & $1 \cdot 000^{*}$ \\
\hline Female & $28(65)$ & $8(62)$ & \\
\hline \multicolumn{4}{|l|}{ Study year } \\
\hline 1st year & $12(28)$ & $1(8)$ & $1 \cdot 000^{\ddagger}$ \\
\hline 2nd year & $19(44)$ & $8(62)$ & \\
\hline graduated & $12(28)$ & $4(30)$ & \\
\hline \multicolumn{4}{|l|}{ Hospital employment } \\
\hline General hospital & $6(14)$ & - & $0 \cdot 002^{\dagger}$ \\
\hline University medical centre & $19(44)$ & $12(92)$ & \\
\hline General hospital & $5(12)$ & - & \\
\hline General hospital & $8(19)$ & $1(8)$ & \\
\hline General hospital & $2(5)$ & - & \\
\hline General hospital & $3(7)$ & - & \\
\hline \multicolumn{4}{|l|}{ Work situation" $^{\pi}$} \\
\hline Clinical setting & - & $5(39)$ & - \\
\hline Outpatient setting & $23(54)$ & $3(23)$ & \\
\hline Clinical \& outpatient setting & $17(40)$ & $4(31)$ & \\
\hline Community setting/ & $3(6)$ & $1(8)$ & \\
\hline \multicolumn{4}{|l|}{ Community \& outpatient setting } \\
\hline \multicolumn{4}{|l|}{ Specialty" } \\
\hline Anaesthesiology & $1(2)$ & $1(8)$ & - \\
\hline Cardiology & $1(2)$ & $2(15)$ & \\
\hline Cardio-thoracic surgery & - & $1(8)$ & \\
\hline Surgery & $10(23)$ & $3(23)$ & \\
\hline Dermatology & $2(5)$ & - & \\
\hline
\end{tabular}


Zwijnenberg, N.C., Bours, G.J.J.W. Nurse practitioners and physician assistants in Dutch hospitals: their role, extent of substitution and facilitators and barriers experienced in the reallocation of tasks. Journal of Advanced Nursing: 2012, 68(6), 1235-1246

\begin{tabular}{|l||l|l|l||}
\hline \multicolumn{1}{|c|}{ Characteristic } & NPs $(n=43)$ & PAs $(n=13)$ & P value \\
\hline \hline Geriatrics & $2(5)$ & & \\
\hline Gynaecology & $2(5)$ & - & \\
\hline \hline Internal medicine & $8(19)$ & - & \\
\hline Paediatrics & $4(9)$ & & \\
\hline Lung diseases & $1(2)$ & & \\
\hline \hline Neurology & $3(7)$ & - & \\
\hline Neonatology & - & $2(15)$ & \\
\hline Nephrology & $5(12)$ & - & \\
\hline Orthopaedics & $3(7)$ & $1(8)$ & \\
\hline \hline Plastic surgery & - & $1(8)$ & \\
\hline Radiology & - & $2(15)$ \\
\hline Rheumatology & $1(2)$ & - \\
\hline
\end{tabular}

*Fisher's exact test.

${ }^{\dagger}$ Pearson chi-square.

†This Fisher's exact test was applied by comparing graduates with students (no distinction was made between 1st year and 2nd year students).

"Numbers were too small to allow a reliable comparison for this result.

Table 3. Average amount of time (hours) and \% of total time spent on tasks during 1 week by nurse practitioners (NPs) and physician assistants (PAs) - questionnaire results

\begin{tabular}{|c|c|c|c|c|c|c|c|c|}
\hline & \multicolumn{3}{|c|}{ NPs $(n=42)$} & \multicolumn{3}{|c|}{ PAs $(n=12)$} & \multirow[b]{2}{*}{$\begin{array}{l}t \text {-test } P \\
\text { value* }^{*}\end{array}$} \\
\hline & & $N$ & $\begin{array}{c}\text { Hours } \\
\text { mean } \\
\text { (SD) }\end{array}$ & $\%$ & $N$ & $\begin{array}{c}\text { Hours } \\
\text { mean } \\
\text { (SD) }\end{array}$ & $\%$ & \\
\hline \multirow{5}{*}{$\begin{array}{l}\text { Direct } \\
\text { patient } \\
\text { care }\end{array}$} & Medical activities & 40 & $5 \cdot 9(4 \cdot 5)$ & $\mid 14 \cdot 2$ & 12 & $\begin{array}{l}16 \cdot 2 \\
(8 \cdot 4)\end{array}$ & $34 \cdot 2$ & $0 \cdot 001$ \\
\hline & Integrated activities & 32 & $3 \cdot 0(3 \cdot 0)$ & $7 \cdot 3$ & 3 & $0 \cdot 3(0 \cdot 6)$ & $0 \cdot 7$ & $<0 \cdot 001$ \\
\hline & Nursing activities & 31 & $2 \cdot 0(2 \cdot 1)$ & $4 \cdot 9$ & 3 & $0 \cdot 2(0 \cdot 4)$ & $0 \cdot 4$ & $<0.001$ \\
\hline & $\begin{array}{l}\text { Activities relating to } \\
\text { coordination and } \\
\text { continuity }\end{array}$ & 41 & $5 \cdot 9(3 \cdot 5)$ & $14 \cdot 1$ & 10 & $4 \cdot 7(4 \cdot 0)$ & 9.9 & $0 \cdot 290$ \\
\hline & $\begin{array}{l}\text { Direct patient care } \\
\text { (total) }\end{array}$ & 42 & $\begin{array}{l}17 \cdot 0 \\
(8 \cdot 0)\end{array}$ & $40 \cdot 6$ & 12 & $\begin{array}{l}21 \cdot 4 \\
(7 \cdot 4)\end{array}$ & $45 \cdot 2$ & $0 \cdot 090$ \\
\hline \multirow{4}{*}{$\begin{array}{l}\text { Indirect } \\
\text { patient } \\
\text { care }\end{array}$} & Consultation & 30 & $1 \cdot 1(1 \cdot 4)$ & $2 \cdot 6$ & 9 & $0 \cdot 8(0 \cdot 7)$ & $1 \cdot 8$ & $0 \cdot 550$ \\
\hline & Referral & 28 & $0 \cdot 9(0 \cdot 9)$ & $2 \cdot 1$ & 6 & $0 \cdot 6(0 \cdot 8)$ & $1 \cdot 4$ & $0 \cdot 523$ \\
\hline & Other activities & 39 & $5 \cdot 2(4 \cdot 0)$ & $12 \cdot 5$ & 12 & $8 \cdot 3(5 \cdot 1)$ & $17 \cdot 6$ & $0 \cdot 032$ \\
\hline & $\begin{array}{l}\text { Indirect patient care } \\
\text { (total) }\end{array}$ & 41 & $7 \cdot 2(4 \cdot 8)$ & $\mid 17 \cdot 2$ & 12 & $9 \cdot 8(5 \cdot 7)$ & $\mid 20 \cdot 8$ & $0 \cdot 114$ \\
\hline
\end{tabular}




\begin{tabular}{|c|c|c|c|c|c|c|c|}
\hline & \multicolumn{3}{|c|}{ NPs $(n=42)$} & \multicolumn{3}{|c|}{ PAs $(n=12)$} & \multirow[b]{2}{*}{$\begin{array}{l}t \text {-test } P \\
\text { value* }^{*}\end{array}$} \\
\hline & $N$ & $\begin{array}{c}\text { Hours } \\
\text { mean } \\
\text { (SD) }\end{array}$ & $\%$ & $N$ & $\begin{array}{c}\text { Hours } \\
\text { mean } \\
\text { (SD) }\end{array}$ & $\%$ & \\
\hline Improving own expertise & 41 & $\begin{array}{l}10 \cdot 8 \\
(8 \cdot 5) \\
\end{array}$ & $25 \cdot 7$ & 12 & $\begin{array}{l}11 \cdot 6 \\
(6 \cdot 4) \\
\end{array}$ & $24 \cdot 5$ & $0 \cdot 756$ \\
\hline Improving expertise of others & 26 & $1 \cdot 0(1 \cdot 2)$ & $2 \cdot 4$ & 5 & $0 \cdot 9(1 \cdot 4)$ & $2 \cdot 0$ & $0 \cdot 804$ \\
\hline Scientific research and innovation & 30 & $2 \cdot 4(3 \cdot 3)$ & $5 \cdot 8$ & 7 & $1 \cdot 7(2 \cdot 2)$ & $3 \cdot 6$ & $0 \cdot 461$ \\
\hline Organizational tasks & 37 & $2 \cdot 5(2 \cdot 0)$ & $5 \cdot 9$ & 5 & $0 \cdot 7(1 \cdot 2)$ & $1 \cdot 5$ & $0 \cdot 006$ \\
\hline Personal time, breaks, other & 18 & $1 \cdot 0(1 \cdot 5)$ & $2 \cdot 3$ & 9 & $1 \cdot 1(1 \cdot 0)$ & $2 \cdot 4$ & $0 \cdot 729$ \\
\hline Total time spent on activities & 42 & $\begin{array}{l}41 \cdot 8 \\
(8 \cdot 3)\end{array}$ & $100 \cdot 0$ & 12 & $\begin{array}{l}47 \cdot 3 \\
(3 \cdot 8)\end{array}$ & $100 \cdot 0$ & $0 \cdot 032$ \\
\hline
\end{tabular}

Only results for the main categories are presented in this table. Any significant differences between NPs and PAs for corresponding activities are described in the results section.

* $P$ values were obtained by comparing average amounts of time (hours) spent on tasks using a $t$-test

Table 4. Tasks performed by nurse practitioners (NPs) and physician assistants (PAs) and content of tasks (figures are numbers (\%)) - interview results

\begin{tabular}{|c|c|c|c|}
\hline & $\begin{array}{c}\text { NPs }(n= \\
43)^{\dagger}\end{array}$ & $\begin{array}{c}\text { PAs }(n= \\
13)^{\dagger}\end{array}$ & $\boldsymbol{P}$ value \\
\hline \multicolumn{4}{|l|}{ Direct patient care } \\
\hline Medical technical activities & $21(50 \cdot 0)$ & $13(100)$ & 0.001* \\
\hline Nursing activities & $30(88 \cdot 2)$ & - & - \\
\hline Taking medical history & $42(97 \cdot 7)$ & $13(100)$ & $1 \cdot 000^{*}$ \\
\hline Taking nursing history & $39(95 \cdot 1)$ & - & - \\
\hline Performing physical examination & $41(95 \cdot 3)$ & $12(92 \cdot 3)$ & $0 \cdot 555^{*}$ \\
\hline Determining medical diagnosis & $39(90 \cdot 7)$ & $12(100)$ & $0 \cdot 566^{*}$ \\
\hline Determining nursing diagnosis & $38(90 \cdot 5)$ & - & - \\
\hline Treatment of patients & $39(90 \cdot 7)$ & $11(84 \cdot 6)$ & $0 \cdot 615^{*}$ \\
\hline Prescribing medication & $21(55 \cdot 3)$ & $7(58 \cdot 3)$ & $0 \cdot 852^{\ddagger}$ \\
\hline Admitting patients & $11(42 \cdot 3)$ & $5(83 \cdot 3)$ & $0 \cdot 172^{*}$ \\
\hline Discharging patients & $15(34 \cdot 9)$ & $9(69 \cdot 2)$ & $\mathbf{0 \cdot 0 2 8 ^ { \ddagger }}$ \\
\hline Communication & $43(100)$ & $13(100)$ & - \\
\hline \multicolumn{4}{|l|}{ Indirect patient care } \\
\hline Communication & $43(100)$ & $13(100)$ & - \\
\hline Ordering laboratory tests & $34(94 \cdot 4)$ & $13(100)$ & $1 \cdot 000^{*}$ \\
\hline Referring/requesting a consultation & $40(93 \cdot 0)$ & $10(76 \cdot 9)$ & $0 \cdot 130 *$ \\
\hline
\end{tabular}


Zwijnenberg, N.C., Bours, G.J.J.W. Nurse practitioners and physician assistants in Dutch hospitals: their role, extent of substitution and facilitators and barriers experienced in the reallocation of tasks. Journal of Advanced Nursing: 2012, 68(6), 1235-1246

\begin{tabular}{|c|c|c|c|}
\hline & $\begin{array}{c}\text { NPs }(n= \\
43)^{\dagger}\end{array}$ & $\begin{array}{c}\text { PAs }(n= \\
13)^{\dagger}\end{array}$ & $P$ value \\
\hline Making rounds & $10(32 \cdot 3)$ & $8(88 \cdot 9)$ & $0 \cdot 006 *$ \\
\hline Updating case history & $26(83 \cdot 9)$ & $7(77 \cdot 8)$ & $0 \cdot 645^{*}$ \\
\hline Administration & $34(94 \cdot 4)$ & $9(100)$ & $1 \cdot 000^{*}$ \\
\hline Evaluating effects/efficiency of care & $36(94 \cdot 7)$ & $7(100)$ & $1 \cdot 000 *$ \\
\hline Case management & $33(76 \cdot 7)$ & $2(16 \cdot 7)$ & $<0 \cdot 001 *$ \\
\hline Contributing to quality of care & $40(95 \cdot 2)$ & $9(75 \cdot 0)$ & $0 \cdot 067^{*}$ \\
\hline Improving own expertise & $42(100)$ & $13(100)$ & - \\
\hline Improving expertise of others & $31(88 \cdot 6)$ & $6(66 \cdot 7)$ & $0 \cdot 138^{*}$ \\
\hline Scientific research and innovation & $27(71 \cdot 1)$ & $2(25 \cdot 0)$ & $0 \cdot 038 *$ \\
\hline \multicolumn{4}{|l|}{ Care according to protocol ${ }^{\S}$} \\
\hline Care not according to protocol & $2(4 \cdot 7)$ & $2(15 \cdot 4)$ & - \\
\hline Care partly according to protocol & $25(58 \cdot 1)$ & $4(30 \cdot 8)$ & \\
\hline Care completely according to protocol & $16(37 \cdot 2)$ & $7(53 \cdot 8)$ & \\
\hline \multicolumn{4}{|l|}{ Content tasks $^{\S}$} \\
\hline New tasks & $1(2 \cdot 3)$ & 0 & - \\
\hline Tasks already performed in the past & $6(14 \cdot 0)$ & $6(46 \cdot 2)$ & \\
\hline New tasks + tasks already performed & $15(34 \cdot 9)$ & $5(38 \cdot 5)$ & \\
\hline $\begin{array}{l}\text { Tasks for which there was not enough capacity }+ \\
\text { tasks already performed }\end{array}$ & $15(34 \cdot 9)$ & 0 & \\
\hline $\begin{array}{l}\text { New tasks + tasks already performed + tasks for } \\
\text { which there was not enough capacity }\end{array}$ & $6(14 \cdot 0)$ & $2(15 \cdot 4)$ & \\
\hline
\end{tabular}

*Fisher's exact test.

${ }^{\dagger}$ In some interviews, not all tasks were specifically mentioned. It is therefore not clear, whether the interviewees performed a task or not. These results were treated as missing values so the $n$ for each task is not always equal to 43 (NPs) or 13 (PAs).

${ }^{\ddagger}$ Pearson chi-square.

${ }^{\S}$ Numbers were too small to allow a reliable comparison for this result. 